\title{
Understanding the reaction mechanism of Kolbe electrolysis on Pt anodes
}

Sihang Liu ${ }^{1 \#}$, Nitish Govindarajan ${ }^{1 \#}$, Hector Prats ${ }^{1,2}$, Karen Chan $^{1^{*}}$

1. Catalysis Theory Center, Department of Physics, Technical University of Denmark (DTU), 2800 Kgs. Lyngby, Denmark

2. Department of Chemical Engineering, University College London, Roberts Building, Torrington Place, London WC1E 7JE, UK

*Corresponding author. Email: kchan@fysik.dtu.dk

\#These authors contributed equally

\section{Abstract}

Kolbe electrolysis has been proposed an efficient electrooxidation process to synthesize (un)symmetrical dimers from biomass-based carboxylic acids. However, the reaction mechanism of Kolbe electrolysis remains controversial. In this work, we develop a DFTbased microkinetic model to study the reaction mechanism of Kolbe electrolysis of acetic acid $\left(\mathrm{CH}_{3} \mathrm{COOH}\right)$ on both pristine and partially oxidized Pt anodes. We show that the shift in the rate-determining step of oxygen evolution reaction (OER) on $\mathrm{Pt}(111) @ \alpha-\mathrm{PtO}_{2}$ surface from $\mathrm{OH}^{*}$ formation to $\mathrm{H}_{2} \mathrm{O}$ adsorption gives rise to the large Tafel slopes, i.e., the inflection zones, observed at high anodic potentials in experiments on Pt anodes. The activity passivation as a result of the inflection zone is further exacerbated in the presence 
of Kolbe species (i.e., $\mathrm{CH}_{3} \mathrm{COO}^{*}$ and $\mathrm{CH}_{3}{ }^{*}$ ). Our simulations find the $\mathrm{CH}_{3} \mathrm{COO}^{*}$ decarboxylation and $\mathrm{CH}_{3}{ }^{*}$ dimerization steps determine the activity of Kolbe reaction during inflection zone. In contrast to the Pt(111)@a-PtO 2 surface, Pt(111) shows no activity towards Kolbe products as the $\mathrm{CH}_{3} \mathrm{COO}^{*}$ decarboxylation step is limiting throughout the considered potential range. This work resolves major controversies in the mechanistic analyses of Kolbe electrolysis on Pt anodes: the origin of the inflection zone, and the identity of the rate limiting step.

\section{Introduction}

With the electrochemical conversion of biomass derivatives as a potential means of green chemical production ${ }^{1-3}$, electro-organic synthesis is experiencing a revival ${ }^{4-10}$ Compared to conventional catalytic (de)-hydrogenation reactions, electrocatalytic conversion schemes offer several advantages: a) they operate at ambient conditions, b) they can be powered by sustainable electricity from wind and solar energy, and c) they require only water as the proton source instead of expensive hydrogen feeds ${ }^{11-13}$. Kolbe electrolysis is a central reaction in electro-organic synthesis since it could be applied to produce longchained hydrocarbons ${ }^{14-16}$. The electrolysis of carboxylic acid was first observed by Faraday ${ }^{17}$, and Hermann Kolbe identified ethane and octane as the respective products of the electrolysis of acetic and valeric $\operatorname{acid}^{18}$. In the past century, a number of experimental studies have investigated its mechanism and the impact of reaction conditions on activity ${ }^{19-23}$.

Scheme 1(a) shows the main mechanisms proposed for (non)-Kolbe electrolysis reactions. ${ }^{14,16}$ Carboxylic acids $(\mathrm{R}-\mathrm{COOH})$ undergo a proton-coupled electron transfer 
(PCET) to form adsorbed carboxyl species $\left(\mathrm{R}-\mathrm{COO}^{*}\right)$. Following decarboxylation of R$\mathrm{COO}^{*}$ which produces $\mathrm{CO}_{2}$ as a by-product, the resultant $\mathrm{R}^{*}$ either dimerizes to form prolonged alkanes ( $\mathrm{R}-\mathrm{R}$, Kolbe reaction, denoted in black) undergoes disproportionation, or loses a further electron to form a $\mathrm{R}^{+}$carbocation species (non-Kolbe reactions, denoted in grey). This $\mathrm{R}^{+}$species can undergo a further $\mathrm{H}^{+}$loss to form alkenes $\left(\mathrm{R}_{2}\right)$, hydrolysis to form alcohols $(\mathrm{R}-\mathrm{OH})$, or react with the deprotonated carboxylic acid (R-COO-) to produce esters. The oxygen revolution reaction (OER, not shown) is the major side reaction that occurs during Kolbe electrolysis at the anode under aqueous conditions, while it is suppressed under anhydrous conditions. ${ }^{19,24} \mathrm{Pt}$ (in oxidized form under operating conditions) is the most widely studied anode for Kolbe electrolysis, and other noble metal oxides like $\mathrm{IrO}_{2}, \mathrm{RuO}_{2}$, and graphene have also been shown to be active for this reaction ${ }^{16,18,25-27}$.

a)

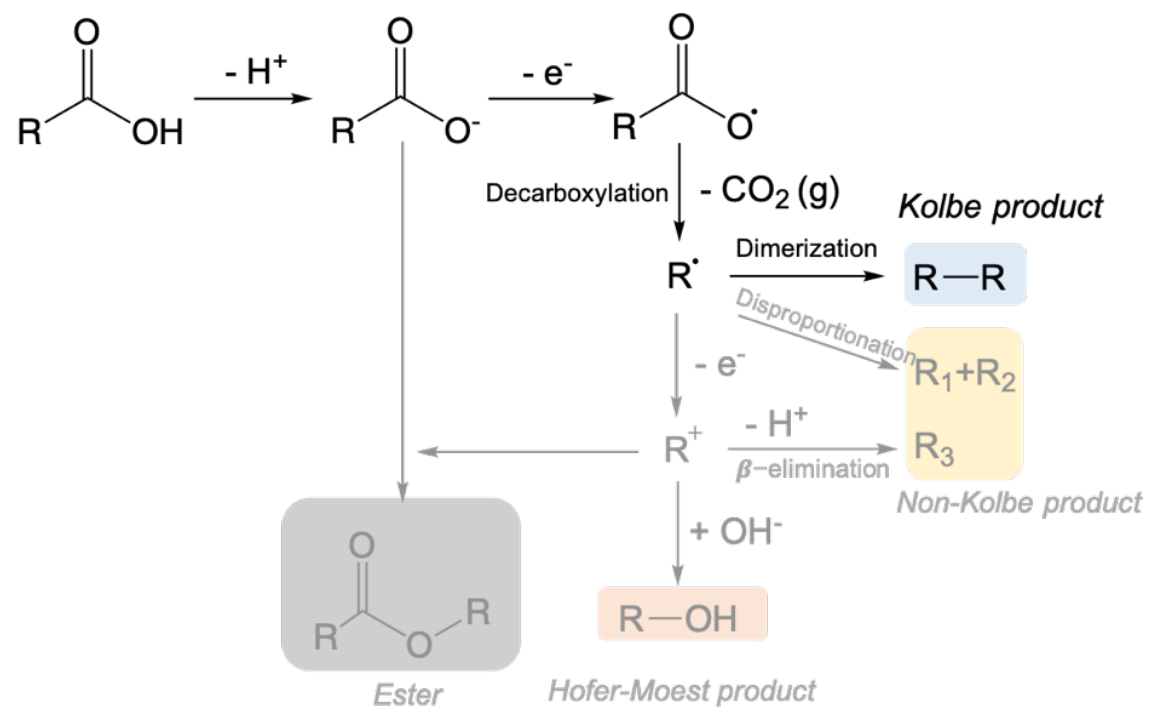

b)

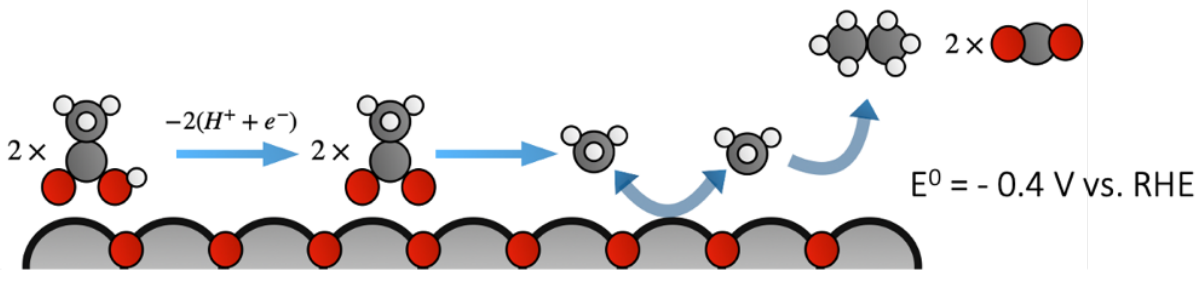


Scheme 1. The reaction network for a) the overall Kolbe electrolysis of carboxylic acids (R-COOH) including the Kolbe reactions resulting in the formation of alkanes (highlighted in blue), and the Non-Kolbe reactions resulting in the formation of alkenes, esters and alcohols (Hofer-Moest product). $R_{1}$ and $R_{2}$ represent disproportionated moieties of the radical $\mathbf{R}^{\bullet} . \mathrm{R}_{3}$ represents the $\beta$ elimination product of $R^{+}$. For example, if $R=\mathrm{CH}_{3}\left(\mathrm{CH}_{2}\right)_{n} \mathrm{CH}_{2} \mathrm{n} \geq 1, \mathrm{R}_{1}=\mathrm{CH}_{3}\left(\mathrm{CH}_{2}\right)_{n} \mathrm{CH}_{3}, \mathrm{R}_{2}=$ $\mathrm{CH}_{3}\left(\mathrm{CH}_{2}\right)_{\mathrm{n}-1} \mathrm{CH}=\mathrm{CH}_{2}, \mathrm{R}_{3}=\mathrm{R}_{2}$. Note that the disproportionation and elimination reactions are not involved in the electrolysis of acetic acid. b) The specific Kolbe reaction considered in this work: the electrolysis of acetic acid $\left(\mathrm{R}=\mathrm{CH}_{3}\right)$ to ethane on Pt anodes. Color coding of atoms: red oxygen, grey - carbon, white - hydrogen and light grey - platinum.

The electro-oxidative conversion of acetic acid to ethane on Pt anodes is the simplest of all Kolbe reactions (Scheme 1b). A prominent feature for this particular process is a flat 'inflection zone' in the current-potential curves (see Figure 3a, below), which coincides with a transition between the predominance of $\mathrm{O}_{2}$ production via OER at lower potentials to ethane production (Kolbe reaction) at higher potentials ${ }^{28-30}$. Kolbe electrolysis of other carboxylic acids on Pt and Ir also show inflection zones at high potentials that accompany the selectivity transition from OER to the Kolbe reaction ${ }^{31-33}$.

In the earliest mechanistic studies, Crum-Brown, Walker and co-workers proposed that Kolbe reaction is a free radical reaction (i.e., homogeneous solution phase reaction), which does not directly involve the electrode surface ${ }^{34-36}$. This free-radical theory was later refuted by rotating electrode ${ }^{33}$ and pulsed electrolysis ${ }^{37}$ experiments on Pt anodes, which showed that the electrode surface promotes the reaction rate and that Kolbe species reversibly adsorb on the Pt electrode. 
Despite the decades of exploration of Kolbe electrolysis, there remain several open questions regarding the exact details of its surface-catalyzed mechanism: i) The possible rate-determining steps (RDS) throughout the operating potentials, ii) The mechanistic origin of the inflection zone on Pt and Ir anodes observed in experiments, and iii) The relationship between Kolbe and OER in aqueous solutions.

All three elementary steps in the surface-catalyzed process in Scheme $\mathbf{1 b}$ have been proposed to be the rate determining step $(\mathrm{RDS})^{19}$. If the first and only electron transfer step, the discharge and deprotonation of $\mathrm{CH}_{3} \mathrm{COOH}^{38}$, were rate limiting, there would be very low coverages of $\mathrm{CH}_{3} \mathrm{COO}^{*}$ and $\mathrm{CH}_{3}{ }^{*}$ species. However, it was reported by transient studies that ethane only starts being produced under high potentials where there are high surface coverages of Kolbe species ${ }^{39-41}$. This build-up of evident coverages of Kolbe species excludes the discharge of $\mathrm{CH}_{3} \mathrm{COOH}$ to $\mathrm{CH}_{3} \mathrm{COO}^{*}$ from being the RDS, such that only the later decarboxylation and/or coupling steps can be rate limiting.

Two theories have been postulated for the presence of the inflection zone observed during the electrolysis of acetic acid on Pt anodes:

Theory l: Cervino et al. suggested that this inflection zone arises from changes in the coverage of the surface species from $\mathrm{CH}_{3} \mathrm{COO}^{*}$ species below the inflection zone to further Kolbe intermediates, probably $\mathrm{CH}_{3}{ }^{*}$, above the inflection zone ${ }^{39}$. They made this postulation based on their observation of a shift in the electrode capacitance at potentials within the inflection zone, determined using electrochemical impedance spectroscopy. This shift in $\mathrm{CH}_{3}{ }^{*}$ coverage was also observed in a voltammetric study by Vasini et al ${ }^{40}$. Theory II: Conway and Dzieciuch ${ }^{20,42,43}$ attributed the inflection zone to a selectivity transition from $\mathrm{O}_{2}$ to ethane. They postulate that this transition occurs upon sufficient 
build-up of a "barrier-layer" film of $\mathrm{CH}_{3} \mathrm{COO}^{*}$ at high enough potentials where $\mathrm{CH}_{3} \mathrm{COOH}$ is favored. The build-up of such a "barrier layer" would hinder the adsorption of $\mathrm{H}_{2} \mathrm{O}$ or $\mathrm{OH}^{-}$species (the reactants of OER) on the surface and thereby suppress $\mathrm{OER}^{33}$. Consistent with this theory, such a film is absent on gold and nickel, which are inactive catalysts for Kolbe electrolysis. However, since there is limited amount of data for the partial (vs. total) current densities towards the various products, it is not clear that OER is suppressed upon the build-up of such a film.

The large Tafel slopes $(>120 \mathrm{mV} / \mathrm{dec})$ of the total current densities in experiments of Kolbe electrolysis was also suggested to arise from the presence of the barrier-layer film of Theory $I I^{19}$. This theory attributes such large Tafel slopes and correspondingly small effective symmetry factors $(\beta<0.5)$ to the reduction in the metal-solution potential drop in the presence of a barrier film of Kolbe species. Moreover, OER on pre-oxidized Pt anodes also shows extremely large Tafel slops (> $500 \mathrm{mV} / \mathrm{dec})$ at high potentials, indicating a barrier-layer of Kolbe species is not necessarily the decisive factor for the large Tafel slopes at high potentials in electrolysis ${ }^{44}$.

As for the nature of electrode surface, Pt should be oxidized under the typical operating conditions ( $>1.5 \mathrm{~V}$ vs. RHE) for Kolbe electrolysis, with the formation of several stable oxide overlayers ${ }^{41,45,46}$. In a previous study, Koper et al. showed that $\alpha-\mathrm{PtO}_{2}$ layer are generated at ca. $1 \mathrm{~V}$ vs. RHE on smooth Pt(111) single crystals in aqueous solution via in situ vibrational spectroscopy ${ }^{47}$. These observations are consistent with density functional theory (DFT) calculations ${ }^{48,49}$ which suggest the formation of $\alpha-\mathrm{PtO}_{2}$ on smooth Pt anodes to be thermodynamically favored above ca. $1 \mathrm{~V}$ vs. RHE. (cf. the Pourbaix diagram in Figure S1). 
In this work, we present a theory-based understanding of mechanisms for Kolbe electrolysis of acetic acid on Pt anodes. Based on DFT calculations of reaction energetics, we find that the strong binding configuration of $\mathrm{CH}_{3} \mathrm{COO}^{*}$ on $\mathrm{Pt}(111)$ at low potentials severely impedes the subsequent decarboxylation steps on this surface, while its weakened in-plane adsorption on the $\mathrm{Pt}(111) @ \alpha-\mathrm{PtO}_{2}$ surface at more oxidizing potentials results in facile $\mathrm{C}-\mathrm{C}$ bond breaking and the subsequent $\mathrm{CH}_{3}{ }^{*}$ coupling step towards the formation of ethane. Combining microkinetic simulations and previously reported experimental studies, we show that the inflection zone observed in Kolbe electrolysis at high anodic potentials arises from a levelling off in OER activity on the oxidized Pt surface. The degree of rate control (DRC) analysis indicates the total activity passivation observed during the inflection zone results from a shift in RDS for the OER from $\mathrm{OH}^{*}$ formation to $\mathrm{H}_{2} \mathrm{O}$ adsorption that is further exacerbated by the presence of Kolbe species. The DRC analysis also shows that later chemical steps (the decarboxylation and $\mathrm{C}-\mathrm{C}$ coupling steps) are rate-determining in the formation of ethane. Finally, we compare and contrast the findings of the present vs. previous mechanistic studies.

\section{Results and discussion}

In what follows, we present the elementary steps and reaction energetics for Kolbe electrolysis of acetic acid and OER on $\mathrm{Pt}(111)$ and $\mathrm{Pt}(111) @ \alpha-\mathrm{PtO}_{2}$ model surfaces, followed by microkinetic simulations to estimate the activity and selectivity towards the various products. 
We considered the following elementary steps for Kolbe electrolysis and the competing

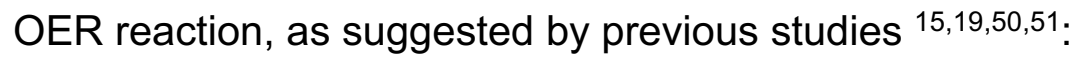

Kolbe reaction:

$\mathrm{CH}_{3} \mathrm{COOH}(\mathrm{aq})+{ }^{*} \leftrightarrow \mathrm{CH}_{3} \mathrm{COO}^{*}+\left(\mathrm{H}^{+}+\mathrm{e}^{-}\right)(\mathrm{x} 2)$

$\mathrm{CH}_{3} \mathrm{COO}^{*} \leftrightarrow{ }^{\mathrm{TS}} \mathrm{CH}_{3}-\mathrm{COO}^{*} \leftrightarrow \mathrm{CH}_{3}{ }^{*}+\mathrm{CO}_{2}(\mathrm{~g})(\mathrm{x} 2)$

$2 \mathrm{CH}_{3}{ }^{*} \leftrightarrow{ }^{T S} \mathrm{CH}_{3}-\mathrm{CH}_{3}{ }^{*} \leftrightarrow \mathrm{C}_{2} \mathrm{H}_{6}(\mathrm{~g})+2^{*}$

Oxygen evolution reaction (OER):

$\mathrm{H}_{2} \mathrm{O}(\mathrm{aq})+{ }^{*} \leftrightarrow \mathrm{H}_{2} \mathrm{O}^{*}$

$\mathrm{H}_{2} \mathrm{O}^{*} \leftrightarrow \mathrm{OH}^{*}+\left(\mathrm{H}^{+}+\mathrm{e}^{-}\right)$

$\mathrm{OH}^{*} \leftrightarrow \mathrm{O}^{*}+\left(\mathrm{H}^{+}+\mathrm{e}^{-}\right)$

$\mathrm{O}^{*}+\mathrm{H}_{2} \mathrm{O}(\mathrm{aq}) \leftrightarrow \mathrm{OOH}^{*}+\left(\mathrm{H}^{+}+\mathrm{e}^{-}\right)$

$\mathrm{OOH}^{*} \leftrightarrow \mathrm{O}_{2}(\mathrm{~g})+\left(\mathrm{H}^{+}+\mathrm{e}^{-}\right)+*$

where * denotes the surface sites for adsorption. In addition to the thermodynamics of the elementary steps, we have computed explicitly ${ }^{\mathrm{TS}} \mathrm{CH}_{3}-\mathrm{COO}^{*}$ and ${ }^{\mathrm{TS}} \mathrm{CH}_{3}-\mathrm{CH}_{3}{ }^{*}$, the transition states corresponding to the decarboxylation of $\mathrm{CH}_{3} \mathrm{COO}^{*}$ and dimerization of $\mathrm{CH}_{3}{ }^{*}$ respectively, which interact significantly with the interfacial electric field and are decisive in the reaction energetics, as we discuss below. We have, for simplicity, neglected non-Kolbe processes in this analysis. 

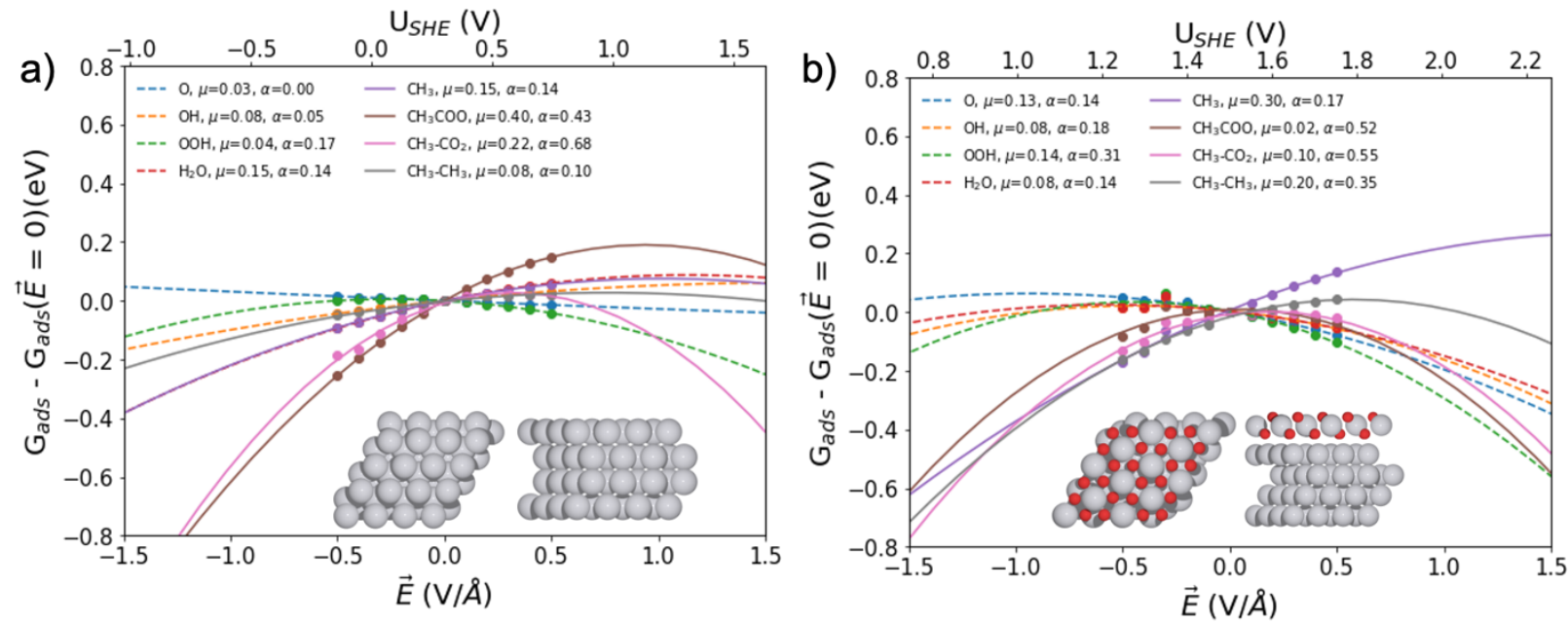

Figure 1. Field effects on reaction intermediates for Kolbe electrolysis and OER on a) Pt(111) and b) Pt(111)@a-PtO 2 surface (model slabs shown with top and side views as insets). Pt(111):

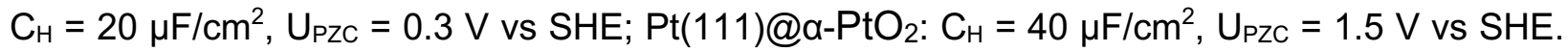
The data points were explicitly calculated with a sawtooth potential and the fitted line was extrapolated from a parabolic fit of these values (details in methods). The dotted lines represent OER intermediates, and the solid lines represent Kolbe reaction intermediates. Parametrized dipole moment $(\mu)$ and polarizability $(\alpha)$ are shown in the insets.

\section{Adsorption strength of reaction intermediates is tuned by the interfacial electric}

\section{field}

Like in e.g., the oxygen reduction reaction ${ }^{52}$ and $\mathrm{CO}_{2}$ reduction reaction ${ }^{53-56}$, we found adsorbate-field interactions to significantly affect the reaction energetics for both Kolbe electrolysis and the competing OER. Figure 1 shows the computed effects of the electric field $(\vec{E})$ for the adsorption energies of the reaction intermediates and transition state energies from Eqs. (1-8) on both the investigated surfaces. The corresponding $U_{S H E}$ is estimated based on the Helmholtz capacitance $\left(\mathrm{C}_{\mathrm{H}}\right)$ and potential of zero charge $\left(\mathrm{U}_{\mathrm{PzC}}\right)$ for Pt (111) and Pt(111)@a-PtO 2 , obtained from Ref ${ }^{57}$. 
At ca. $1.0 \mathrm{~V} / \AA$, there are significant field stabilizations $(\sim 0.1-1 \mathrm{~V})$ of both OER and Kolbe reaction intermediates. Amongst the OER intermediates, we find $\mathrm{OOH}^{*}$ to have the largest stabilizing effect at higher potentials due to its comparatively large polarizability $(\alpha)^{52}$.With the exception of $\mathrm{OOH}^{*}$, the field effects on the Kolbe intermediates are generally larger than those for OER. As we discuss below, the field-adsorbate interactions for both the $\mathrm{C}-\mathrm{C}$ bond breaking (Eq. 2) and $\mathrm{CH}_{3}$ dimerization (Eq. 3) steps have an important influence on the energetics of the Kolbe reaction on both surfaces considered.

a)

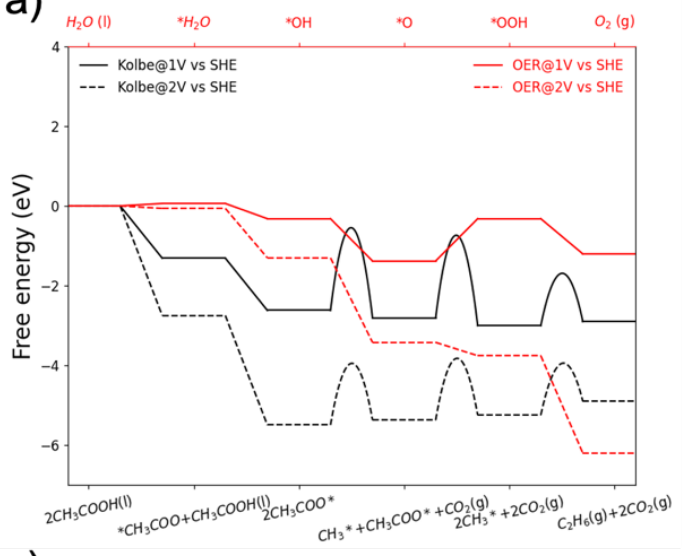

c)

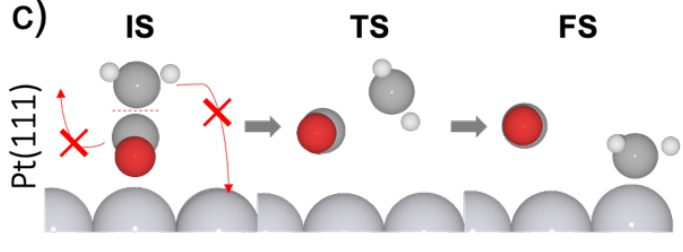

b)

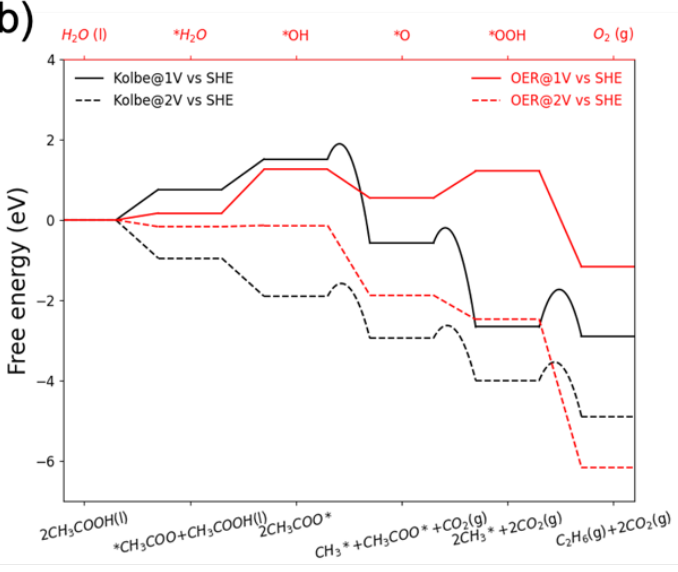

d)

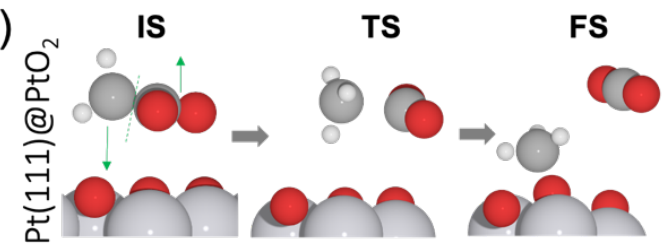

Figure 2. Free energy diagrams of acetic acid electrooxidation (Kolbe) and OER on a) Pt(111) and b) $\mathrm{Pt}(111) @ \alpha-\mathrm{PtO}_{2} . \mathrm{U}_{\mathrm{SHE}}=1,2 \mathrm{~V}$ at $\mathrm{pH}=4.6$ and $298 \mathrm{~K}$ are applied here to show the potential effect of potential on reaction energetics, with Kolbe reaction in black and OER in red. As for OER, only the thermodynamics of proton-coupled electron transfer steps are considered, which might result in an overestimation of OER activity obtained using microkinetic simulations. This approximation also applies to the deprotonation of $\mathrm{CH}_{3} \mathrm{COOH}$ involved in the Kolbe reaction. c) and d) representative configurations of the initial state (IS), transition state (TS) and final state 
(FS) obtained using nudged elastic band (NEB) calculations of the C-C bond breaking step of $\mathrm{CH}_{3} \mathrm{COO}^{*}$ to $\mathrm{CH}_{3}{ }^{*}$ and $\mathrm{CO}_{2(\mathrm{~g})}$ on $\mathrm{Pt}(111)$ and $\mathrm{Pt}(111) @ \alpha-\mathrm{PtO}_{2}$ respectively.

\section{Free energy diagrams indicate facile Kolbe activity on oxidized metal surfaces at high potentials}

Figures 2 shows the calculated free energy profiles for Kolbe electrolysis of acetic acid and the competing OER reaction on $\mathrm{Pt}(111)$ and $\mathrm{Pt}(111) @ \alpha-\mathrm{PtO}_{2}$, respectively. We include the elementary steps of Eqs (1-8) at potentials of 1 , and $2 V_{S H E}$ under reaction conditions of $\mathrm{pH}=4.6, \mathrm{C}_{\mathrm{a}}=1 \mathrm{M}, \mathrm{T}=298 \mathrm{~K}$. The field effects, shown in Figure 1, are also included. In the Kolbe reaction, only the initial deprotonation steps (which occurs twice in the overall reaction) are electrochemical (i.e., involve a proton-coupled electron transfer), while the subsequent decarboxylation and dimerization steps are chemical. For comparison, the free energy diagrams without adsorbate-field interactions are shown in Figure S6.

In general, $\mathrm{Pt}(111) @ \alpha-\mathrm{PtO}_{2}$ binds both Kolbe and OER species more weakly than Pt(111). Specifically, $\mathrm{CH}_{3} \mathrm{COOH}$ deprotonation is much more sluggish on $\mathrm{Pt}(111) @ \alpha-\mathrm{PtO} 2$ than $\mathrm{Pt}(111)$ at $1 \mathrm{~V}_{\mathrm{SHE}}$ in Figure $\mathbf{2 a}$ and $\mathbf{2} \mathbf{b}$, indicating a high overpotential for building up $\mathrm{CH}_{3} \mathrm{COO}^{*}$ species on $\mathrm{Pt}$ oxides. Consequently, OER species should dominate on $\mathrm{Pt}(111) @ \alpha-\mathrm{PtO}_{2}$ at low potentials, while $\mathrm{CH}_{3} \mathrm{COO}^{*}$ could already build up on $\mathrm{Pt}(111)$.

At higher potentials, the adsorption of $\mathrm{CH}_{3} \mathrm{COO}^{*}$ becomes facile on both surfaces. The defining differences between the two surfaces is in the adsorption configuration of $\mathrm{CH}_{3} \mathrm{COO}^{*}$ and the magnitude of the subsequent $\mathrm{C}-\mathrm{C}$ bond breaking barrier. These differences result in surmountable barriers for the Kolbe reaction on $\mathrm{Pt}(111) @ \alpha-\mathrm{PtO}_{2}$ but not on $\mathrm{Pt}(111)$. Figures $\mathbf{2 c}$ and $\mathbf{2 d}$ show side and top views of $\mathrm{CH}_{3} \mathrm{COO}^{*}$ on the two 
respective surfaces. On $\mathrm{Pt}(111), \mathrm{CH}_{3} \mathrm{COO}^{*}$ is adsorbed in a stable bidentate configuration, which has been confirmed by attenuated total reflection configuration (ATRFTIRS) studies ${ }^{58}$. The corresponding free energy for the proton-electron transfer step (Eq. 1) is exergonic, even at $0 V_{S H E}$, well below the oxidizing potentials at which Kolbe electrolysis occurs. In contrast, $\mathrm{CH}_{3} \mathrm{COO}^{*}$ is weakly adsorbed in-plane on $\alpha-\mathrm{PtO}_{2}$. The free energy for the proton-electron transfer step (Eq. 1) becomes exergonic only at 1.33 VSHE.

The subsequent C-C bond breaking (the decarboxylation step, Eq. 2), on the other hand, is much more facile for the $\mathrm{CH}_{3} \mathrm{COO}^{*}$ on $\alpha-\mathrm{PtO}_{2}$ than $\mathrm{Pt}(111)$. As illustrated in Figure 2c, there is a large configurational energy penalty for the rotation required to break the $\mathrm{C}-\mathrm{C}$ bond on the $\mathrm{Pt}(111)$ surface. In contrast, the in-plane configuration of $\mathrm{CH}_{3} \mathrm{COO}^{*}$ on $\alpha-$ $\mathrm{PtO}_{2}$ (cf. Figure 2d) enables a pseudo-homogeneous path for $\mathrm{C}-\mathrm{C}$ bond breaking that is much more facile.

Both chemical steps exhibit potential dependence to some extent due to adsorbate dipole-field interactions (Figures 1a, b). These interactions result in a reduction in the barrier of $\mathrm{C}-\mathrm{C}$ bond breaking from $2.07 \mathrm{eV}$ to $1.55 \mathrm{eV}$ on $\mathrm{Pt}(111)$ and a slight increase from 0.20 to $0.23 \mathrm{eV}$ on $\mathrm{Pt}(111) @ \alpha-\mathrm{PtO}_{2}$ when the potential increases from $1 \mathrm{~V}$ to $2 \mathrm{~V}_{\text {SHE }}$ in (Figures 2a, b). Despite the field stabilization, the $\mathrm{C}-\mathrm{C}$ bond breaking barrier on $\mathrm{Pt}(111)$ is still too large for any activity towards the Kolbe reaction at ca. $2 V_{\text {SHE. }}$

The subsequent $\mathrm{CH}_{3}-\mathrm{CH}_{3}$ dimerization barrier (Eq. 3) is also field-stabilized on both surfaces. The calculated barriers change from 1.31 to $1.29 \mathrm{eV}$ on $\mathrm{Pt}(111)$ and from 0.76 to $0.08 \mathrm{eV}$ on $\mathrm{Pt}(111) @ \alpha-\mathrm{PtO}_{2}$; the reduced barrier of $\mathrm{CH}_{3}{ }^{*}$ dimerization on $\alpha-\mathrm{PtO}_{2}$ surface further facilitates ethane $\left(\mathrm{C}_{2} \mathrm{H}_{6}\right)$ formation. 
In summary, the field-dependent reaction energetics predict that the Kolbe reaction proceeds on $\mathrm{Pt}(111) @ \alpha-\mathrm{PtO}_{2}$ but not $\mathrm{Pt}(111)$ at high potentials (ca. $2 \mathrm{~V}_{\mathrm{SHE}}$ ). On $\mathrm{Pt}(111) @ \alpha-\mathrm{PtO}_{2}$ at this potential range, there is a buildup of $\mathrm{CH}_{3} \mathrm{COO}^{*}$ coverage, followed by facile $\mathrm{C}-\mathrm{C}$ bond breaking and $\mathrm{CH}_{3}-\mathrm{CH}_{3}$ dimerization. In contrast, due to the high barriers for the $\mathrm{C}-\mathrm{C}$ bond breaking of $\mathrm{CH}_{3} \mathrm{COO}^{*}$ on $\mathrm{Pt}(111)$, a coverage of $\mathrm{CH}_{3} \mathrm{COO}^{*}$ would simply build up and act as a surface poison.
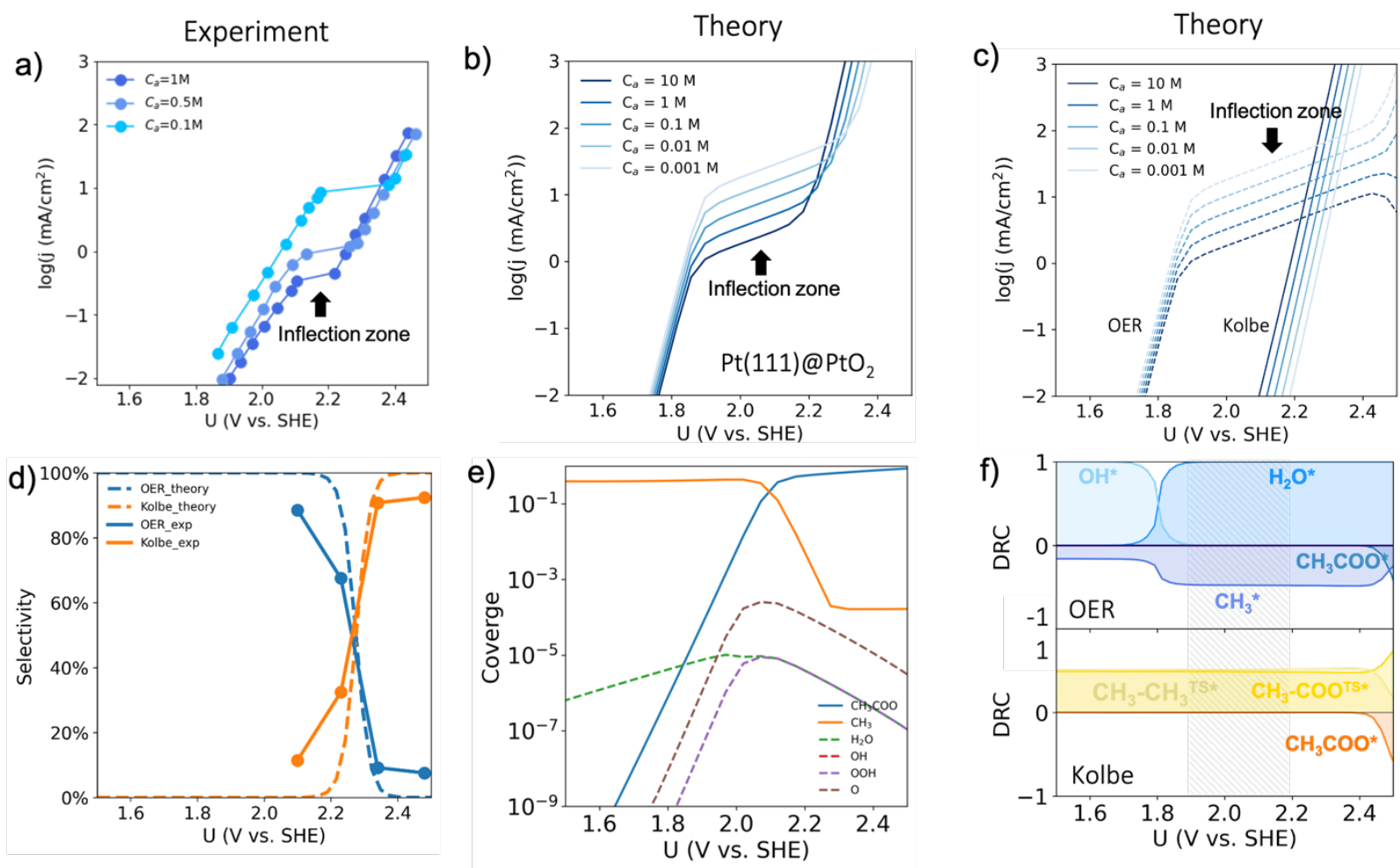

Figure 3. Experimental observations and microkinetic modeling results for Kolbe electrolysis of acetic acid on Pt anodes. a) Experimental polarization curves of Kolbe electrolysis in sodium acetate and acetic acid solutions on a polished Pt anode with different acetic acid concentrations $\left(\mathrm{C}_{\mathrm{a}}=0.1,0.5\right.$ and $\left.1 \mathrm{M}\right), \mathrm{pH}=4.6$, at room temperature. The inflection zone is highlighted. $\left.{ }^{28} \mathrm{~b}\right)$ Simulated polarization curves on $\mathrm{Pt}(111) @ \alpha-\mathrm{PtO}_{2}$ surface using $\mathrm{C}_{\mathrm{H}}=40 \mu \mathrm{F} / \mathrm{cm}^{2}, \mathrm{U}_{\mathrm{PZC}}=1.5 \mathrm{~V}_{\mathrm{SHE}}$ c) Simulated partial current density towards OER (dashed lines) and Kolbe reaction on 
$\mathrm{Pt}(111) @ \alpha-\mathrm{PtO}_{2}$ (solid lines) d) Experimenta ${ }^{28}$ and simulated selectivity of Kolbe reaction vs. OER on $\mathrm{Pt}$ anode with $\mathrm{C}_{\mathrm{a}}=1 \mathrm{M}, \mathrm{pH}=4.6$, at room temperature; e) Simulated coverages of key adsorbates involved in the Kolbe and OER reactions on Pt(111)@a-PtO ${ }_{2}$ under the same conditions of $d)^{28}$; f) Degree of rate control (DRC) analysis on Pt(111)@a-PtO 2 (The grey region represents inflection zone). Conditions for microkinetic simulations: $\mathrm{pH}=4.6, \mathrm{~T}=298 \mathrm{~K}, \mathrm{C}_{\mathrm{a}}=$ $0.001,0.01,0.1,1,10 \mathrm{M}$.

\section{Microkinetic modeling suggests Kolbe electrolysis to be limited by decarboxylation and/or dimerization}

Based on the field-dependent energetics illustrated above, we develop a mean-field microkinetic model to determine the theoretical activity and selectivity of Kolbe electrolysis, which we directly compare to the experimental observations.

The experimental polarization curves taken from $\operatorname{Ref}^{28}$ are displayed in Figure $\mathbf{3 a}$. Inflection zones, nearly flat regions in the plots, appear above $2.1 \mathrm{~V}_{\mathrm{SHE}}$. The onset current density reduces with an increase in the initial concentration of acetic acid in the electrolyte. The selectivity shifts from OER $\left(\mathrm{O}_{2}\right.$ production) towards Kolbe reaction $\left(\mathrm{CO}_{2}\right.$ and $\mathrm{C}_{2} \mathrm{H}_{6}$ production) within the inflection zone. Both the production of $\mathrm{O}_{2}$ and $\mathrm{C}_{2} \mathrm{H}_{6}$ grow with increasing potentials, but the increase in $\mathrm{C}_{2} \mathrm{H}_{6}$ production is more acute than $\mathrm{O}_{2}$ production, which gives rise to the selectivity shift. The total selectivity of OER and Kolbe reactions reported in the experiments is ca. $90 \%$, which may be due to side (e.g., NonKolbe and electrode oxidation) reactions or because methane that can be formed as a minor product from $\mathrm{CH}_{3}{ }^{*}$ was not accounted for in the product analysis in $\operatorname{Ref}^{28}$.

The qualitative features in the simulated total $j$ vs. USHE on Pt(111)@a-PtO 2 (Figure 3b) are consistent with the experimental observations in terms of the presence of the 
"inflection zone" (region of passivated activity) in ${ }^{59}$. The simulated partial current densities in Figure 3C show the inflection zone arises from the suppression of OER activity, which occurs along with a steady increase in the activity for the Kolbe reaction at high potentials. The selectivity shift from OER to Kolbe reaction is shown in Figure 3d, where our simulated results agree well with the experiment. Within the potential range 1.5-2.5 V VHE, Kolbe species, i.e., first $\mathrm{CH}_{3}{ }^{*}$ and later $\mathrm{CH}_{3} \mathrm{COO}^{*}$, dominate on the surface, while OER species, e.g., $\mathrm{H}_{2} \mathrm{O}^{*}$, peaks at ca. $2 \mathrm{~V}_{\mathrm{SHE}}$ and then decreases, shown in Figure 3e.

The DRC in Figure $\mathbf{3 f}$ also suggests that in the inflection zone, Kolbe reaction is limited by the barrier for $\mathrm{CH}_{3}{ }^{*}$ coupling $\left({ }^{\mathrm{TS}} \mathrm{CH}_{3}-\mathrm{CH}_{3}{ }^{*}\right)$ as well as the coverage of preceding species as determined by ${ }^{\mathrm{TS}} \mathrm{CH}_{3}-\mathrm{COO}^{*}$. The small simulated Tafel slope $(<59 \mathrm{mV} / \mathrm{dec})$ is consistent with a rate-limiting step after the first PCET step. Considering the intrinsic error in DFT calculations (ca. $0.2 \mathrm{eV}$ ), we suggest that the Kolbe reaction can be determined by decarboxylation and/or dimerization step at high potentials. 


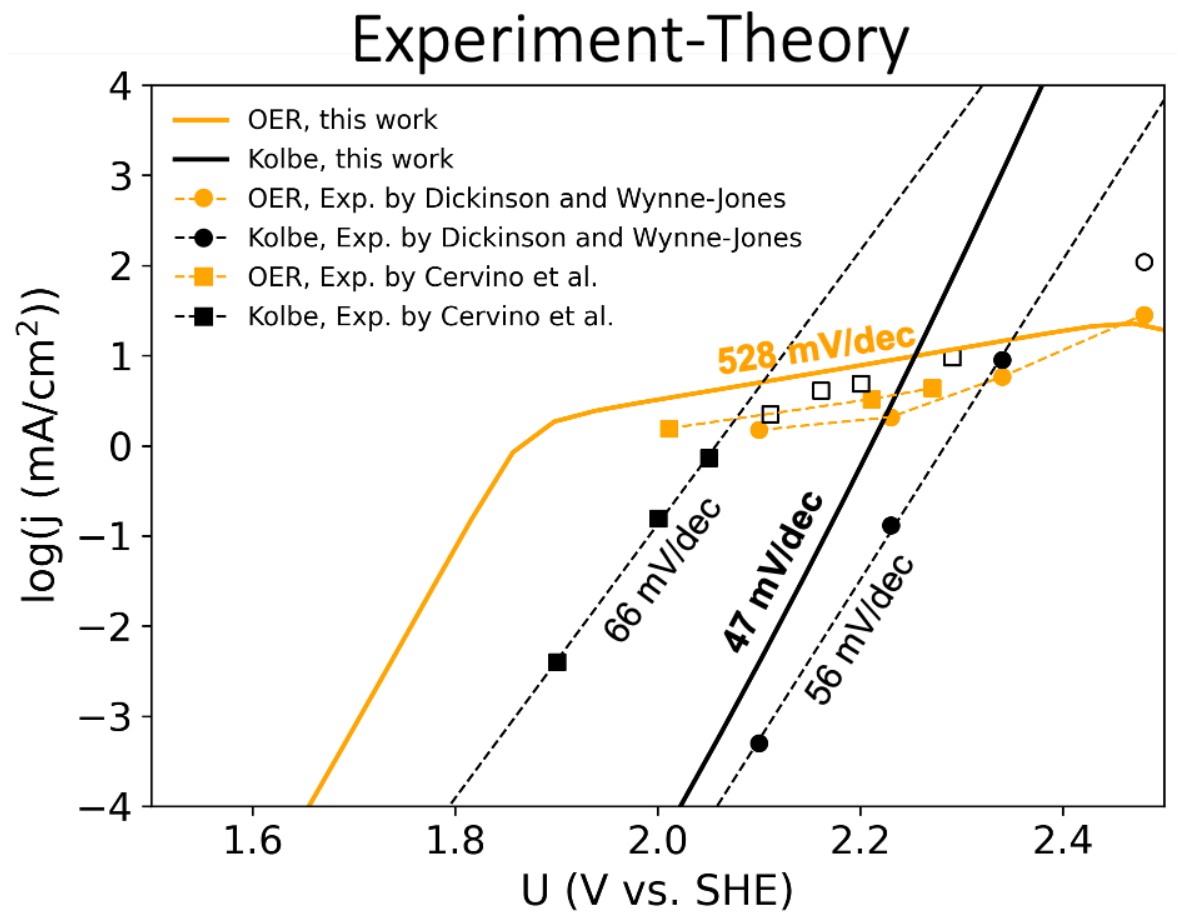

Figure 4. The experimental (on oxidized Pt anodes) and simulated partial polarization curves on $\mathrm{Pt}(111) @ \mathrm{\alpha}-\mathrm{PtO}_{2}$ of Kolbe electrolysis of acetic acid. Only the first three data points of the experimental Kolbe activity were used for fitting the Tafel slopes due to the potential mass transport limitations of products or other side reactions at higher potentials. Experiments by Dickinson and Wynne-Jones: $1 \mathrm{M}$ acetic acid, $\mathrm{T}=298 \mathrm{~K}, \mathrm{pH}=4.6^{28}$; Experiments by Cervino et al: $1 \mathrm{M}$ acetic acid, $\mathrm{T}=303 \mathrm{~K}, \mathrm{pH}=4.9^{39}$. Conditions for microkinetic simulations: $\mathrm{pH}=4.6, \mathrm{~T}=298$ $\mathrm{K}, 1 \mathrm{M}$ acetic acid.

We directly compare the partial activities towards OER and Kolbe products between theory and experiment. The large Tafel slope of $528 \mathrm{mV} / \mathrm{dec}$ simulated for OER during inflection zone is comparable to that in experiments. The calculated Tafel slopes for Kolbe reaction is $47 \mathrm{mV} / \mathrm{dec}$, in good agreement with experimental values ca. $56-66 \mathrm{mV} / \mathrm{dec}$ in Ref ${ }^{28,39}$, indicating it is not the $\mathrm{CH}_{3} \mathrm{COO}^{*}$ formation (i.e., the first electron transfer step) but 
a later step that is limiting, i.e., the decarboxylation of $\mathrm{CH}_{3} \mathrm{COO}^{*}$ and/or dimerization of $\mathrm{CH}_{3}{ }^{*}$.

We note that our microkinetic model presents a negative one-third order dependence of activity on $\mathrm{CH}_{3} \mathrm{COOH}$ concentration shown in Figure S7, while the experimental dependence is almost negative first order (Figure S8). The degree of rate control (DRC) analysis in Figure $\mathbf{3 f}$ shows that OER activity (top panel) within inflection zone is determined by $\mathrm{H}_{2} \mathrm{O}^{*}$ adsorption and worsened by $\mathrm{CH}_{3}{ }^{*}$ formation, which would in principle give rise to a negative first-order dependence on initial $\mathrm{CH}_{3} \mathrm{COOH}$ concentration in solution. The discrepancy between the model and experiment could result from the sensitivity of adsorbate interaction parameters $(\epsilon)$ applied to account for adsorbateadsorbate interactions in our model ${ }^{60,61}$. We show that applying a smaller adsorbate interaction factor for all species leads to ca. three-fourth order of dependence in Figure S10. Given the uncertainty in determining $\epsilon$, the negative dependence on reactant concentration still holds.

The low-overpotential part of the inflection zone arises from OER, and occurs even without acetic acid

In order to deconvolute the effects of OER and Kolbe reaction, we explored OER in the absence of any Kolbe reaction (i.e., $C_{a}=0 \mathrm{M}$ ) on Pt oxide using microkinetic modeling. In Figure S11a, we show that without $\mathrm{CH}_{3} \mathrm{COOH}$, the simulated OER activity on $\mathrm{Pt}(111) @ \alpha-\mathrm{PtO}_{2}$ is much higher than with $\mathrm{CH}_{3} \mathrm{COOH}$ as shown with dotted lines in Figure 3c. In Figure S11b, we show that the coverages of OER species, are almost constant at high potentials, without the decrease that we observe in the presence of $\mathrm{CH}_{3} \mathrm{COOH}$. 
Interestingly, the OER also reaches inflection zone at higher potentials compared to the model with acetic acid. This is due to $\mathrm{H}_{2} \mathrm{O}^{*}$ adsorption, i.e., a chemical step, is determining the OER activity at high potentials, where all PCET steps become facile. Our observations also indicate that reducing the partial pressure of water $\left(\mathrm{p}_{\mathrm{H} 2 \mathrm{O}}\right)$ in our microkinetic simulation lowers the OER activity within the inflection zone (cf. Figure S13). In the limit of anhydrous conditions $\left(\mathrm{p}_{\mathrm{H} 2 \mathrm{O}}=0\right)$, there is no inflection zone, as there is no competition between OER with the Kolbe reaction in this extreme case. This conclusion is also in line with previous observations that the Kolbe synthesis proceeds with optimal selectivities in nonaqueous media, e.g., in pure carboxylic acid solutions ${ }^{41,62}$, methanol ${ }^{63,64}$ or other solvents ${ }^{16}$.

We note that the appearance of an inflection zone during OER has not been discussed in previous studies, probably due to the limited potential ranges (ca. 1.2- $2.0 \mathrm{~V}_{\mathrm{SHE}}$ ) typically investigated in previous studies. There is one study where the OER polarization curve on $\mathrm{PtO}_{2}$ films beyond $2 \mathrm{~V}_{\text {SHE }}$ was reported where we observe the appearance of an inflection zone with a large tafel slope $(>500 \mathrm{mV} / \mathrm{dec} \text { ) (cf. Figure S12 })^{46}$. It has been postulated that electron tunneling issues due to the formation of thick Pt oxide films might be the reason for the observed increase in Tafel slopes at high anodic potentials ${ }^{65-67}$. We anticipate that future studies can investigate the exact origin of the dramatic increase in tafel slopes during OER.

In the context of the discussions on the inflection zone observed during OER discussed above, we emphasize the importance of accounting for $\mathrm{H}_{2} \mathrm{O}$ binding as an explicit step in OER modeling studies, as this step is typically excluded based on the conventional assumption that $\mathrm{H}_{2} \mathrm{O}$ adsorption is a facile chemical step ${ }^{68}$. However, the exclusion of 
$\mathrm{H}_{2} \mathrm{O}$ adsorption in kinetic analysis could lead to following pitfalls: 1. For surfaces that bind $\mathrm{H}_{2} \mathrm{O}$ strongly, such an exclusion could intrinsically underestimate the actual deprotonation barrier of $\mathrm{H}_{2} \mathrm{O}^{*} ; 2$. The competition for surface sites between $\mathrm{H}_{2} \mathrm{O}$ and species for other reactions cannot be captured if the $\mathrm{H}_{2} \mathrm{O}$ adsorption step is excluded in the modeling, e.g., like in $\mathrm{H}_{2} \mathrm{O}^{*}$ vs $\mathrm{CH}_{3} \mathrm{COO}^{*}$ in this work.

\section{Bare $\mathrm{Pt}(111)$ shows no activity for the Kolbe reaction in aqueous phase} In contrast to Pt(111)@a-PtO 2 , we find only OER occurs on Pt(111), while Kolbe reaction is prohibited by the high decarboxylation barrier shown in Figure 2a. The DRC analysis in Figure $\mathbf{S} 18$ shows that Kolbe reaction is hindered by the formation of $\mathrm{CH}_{3}-\mathrm{COO}^{T S^{*}}$, and later also by the accumulation of $\mathrm{CH}_{3} \mathrm{COO}^{*}$. As shown in Figure S19, the coverage of OER species decreases dramatically after ca. $1.1 \mathrm{VSHE}$, while $\mathrm{CH}_{3} \mathrm{COO}^{*}$ is swiftly building up. Finally, the consequent over-accumulation of $\mathrm{CH}_{3} \mathrm{COO}^{*}$ shown in poisons the surface and leads to dramatic activity decline beyond 1.1 $\mathrm{V}_{\text {SHE }}$ shown in Figure S20.

\section{Sensitivity analysis of the microkinetic model}

To evaluate the generality of the conclusions of our microkinetic model, we perform sensitivity analyses on a few important model parameters as discussed below.

First, we note that only the reaction thermodynamics of the proton-electron transfers in Eqs 4-8 were considered for OER in our microkinetic model (i.e., these reactions are assumed to have negligible barriers) $)^{51,69}$, which might result in an overestimation of the OER activity on both surfaces considered. In Figure $\mathbf{S 1 4}$ we show a sensitivity analysis of the barrier for $\mathrm{O}^{*}$ to $\mathrm{OOH}^{*}$, which has been shown to be potentially determining PCET 
step in ORR on oxide surfaces ${ }^{51}$. With additional PCET barriers, the inflection zone still exists. And there is only a slight shape change of the Tafel plot at a barrier of $0.6 \mathrm{eV}$ at ca. 1.9 $\mathrm{V}_{\text {SHE. }}$ A high barrier of $1 \mathrm{eV}$ results in the disappearance of the inflection zone as OER will not be able to compete with the Kolbe reaction under these conditions.

Second, in previous studies, the electrode capacitance and potential of zero charge have been found change during Kolbe electrolysis ${ }^{39,46}$ and the surface oxidation of the $\mathrm{Pt}$ electrode ${ }^{70}$. For simplicity, we had applied constant values of $\mathrm{C}_{H}$ and $U_{\mathrm{PZC}}$ in our model. In Figure S15, we evaluated the sensitivity of simulated polarization curve of the $\mathrm{Pt}(111) @ \alpha-\mathrm{PtO}_{2}$ surface to different values of $\mathrm{C}_{\mathrm{H}}$ and $\mathrm{U}_{\mathrm{PZC}}$. Similar shapes of polarization curves were obtained, indicating the overall activity trend is largely unaffected by these parameters. However, we noticed that the magnitude of the overall activity is sensitive to $\mathrm{C}_{\mathrm{H}}$ and UPZC: Low $\mathrm{C}_{\mathrm{H}}$ and $\mathrm{U}_{\mathrm{PZC}}$ mean larger interfacial fields, which stabilize the Kolbe intermediates further than those for OER. This difference in field-adsorbate stabilization reduces the extent of the inflection zone. Figure $\mathbf{S 1 6}$ shows the polarization curves computed without field-adsorbate stabilization. The inflection zone is still present, but the onset of Kolbe electrolysis occurs at higher potentials.

\section{Revisiting previously proposed mechanisms}

Based on our simulation results, we revisit the old mechanistic theories proposed in the past century for the Kolbe electrolysis.

Firstly, we find that the coverages of the Kolbe reaction intermediates are not negligible even on the oxidized Pt surface, indicating that Kolbe electrolysis is not a pure solution phase (i.e., homogeneous) reaction, but involves adsorbed species, i.e., $\mathrm{CH}_{3} \mathrm{COO}^{*}$ and 
$\mathrm{CH}_{3}{ }^{*}$. This finding refutes the free-radical theory ${ }^{34-36}$, and other homogeneous proposals of Kolbe electrolysis, e.g., hydrogen peroxide theory ${ }^{71}$, in favor of heterogeneous reaction mechanisms proposed by Conway, Fioshin, and Fleischmann ${ }^{19}$.

Secondly, our model shows that the RDS of OER on Pt oxide surface changes from a $\mathrm{OH}^{*}$ formation (before inflection zone) to $\mathrm{H}_{2} \mathrm{O}$ adsorption (during inflection zone), leading to a passivated OER activity at high potentials, which is further exacerbated by the existence of Kolbe species. In contrast to the OER model without the Kolbe reaction, OER activity including Kolbe electrolysis is passivated ca. $0.2 \mathrm{~V}_{\mathrm{SHE}}$ earlier and lowered by several orders of magnitude. This observation is in agreement with the postulation by Vijh and Conway that OER activity is suppressed at high potentials due to the formation of "barrier-layer" films of Kolbe species ${ }^{41}$.

Finally, our DRC analysis indicates that at high anodic potentials, Kolbe reaction is not determined by the discharge of $\mathrm{CH}_{3} \mathrm{COOH}$ on the $\mathrm{PtO}_{2}$ surface (cf. Eqn 1), but by the following decarboxylation and dimerization steps. This result refutes the conclusion in $\operatorname{Ref}^{38}$ that initial discharge of acetate anion is the RDS during the Kolbe electrolysis of acetic acid. Given the uncertainties in DFT calculation, our model shows that both decarboxylation of $\mathrm{CH}_{3} \mathrm{COO}^{*}$ and $\mathrm{CH}_{3}{ }^{*}$ dimerization can determine Kolbe activity on $\mathrm{PtO}_{2}$ during the inflection zone. Beyond the inflection zone, Kolbe reaction is mainly determined by the $\mathrm{CH}_{3} \mathrm{COO}^{*}$ decarboxylation. Our simulation results indicate that the RDS for Kolbe reaction does not involve a PCET step, in contrast to previous proposals that directly involve the discharge and deprotonation of acetic acid in the RDS ${ }^{19}$.

\section{Conclusions}


To summarize, we presented a detailed mechanistic study of the Kolbe electrolysis of acetic acid on $\mathrm{Pt}$ anodes that helps resolve the origin of inflection zone at high overpotentials and the controversy over possible RDS. The field-corrected free energy diagrams indicate that the sluggish deprotonation of $\mathrm{CH}_{3} \mathrm{COOH}$ on $\mathrm{Pt}$ oxide in aqueous conditions leads to a high overpotential for Kolbe products. The microkinetic simulation shows that the experimentally observed inflection zones (passivated total activity) at high potentials arise from a shift in RDS of OER from ${ }^{*} \mathrm{OH}$ formation to $\mathrm{H}_{2} \mathrm{O}$ adsorption on oxidized surfaces, which is further exacerbated by the onset of the Kolbe reaction. The RDS for Kolbe reaction during inflection zone is unlikely to be the deprotonation and discharge of acetic acid, but the later chemical steps of $\mathrm{CH}_{3} \mathrm{COO}^{*}$ decarboxylation and/or $\mathrm{CH}_{3}{ }^{*}$ dimerization, which are promoted by adsorbate-field interactions at high potentials. The results displayed above suggest that materials with stronger $\mathrm{CH}_{3} \mathrm{COO}^{*}$ adsorption and weaker $\mathrm{H}_{2} \mathrm{O}^{*}$ binding in aqueous conditions could lead to lower overpotentials and higher selectivity towards Kolbe products. Future studies will evaluate new materials for these binding properties.

\section{Data Availability}

All the raw data needed to reproduce the figures in the article will be made available in the CatTheoryDTU Gihub account upon publication.

\section{Acknowledgements}

This work was supported by a research grant (29450) from VILLUM FONDEN. 


\section{References:}

1. Yoshida, J., Kataoka, K., Horcajada, R., and Nagaki, A. (2008). Modern Strategies in Electroorganic Synthesis. Chem. Rev. 108, 2265-2299.

2. Wiebe, A., Gieshoff, T., Möhle, S., Rodrigo, E., Zirbes, M., and Waldvogel, S.R. (2018). Electrifying Organic Synthesis. Angew. Chem. Int. Ed. 57, 5594-5619.

3. Zhu, C., Ang, N.W.J., Meyer, T.H., Qiu, Y., and Ackermann, L. (2021). Organic Electrochemistry: Molecular Syntheses with Potential. ACS Cent. Sci. 7, 415-431.

4. Elsherbini, M., and Wirth, T. (2019). Electroorganic Synthesis under Flow Conditions. Acc. Chem. Res. 52, 3287-3296.

5. Pollok, D., and Waldvogel, S.R. (2020). Electro-organic synthesis - a $21^{\text {st }}$ century technique. Chem. Sci. 11, 12386-12400.

6. Wiebe, A., Riehl, B., Lips, S., Franke, R., and Waldvogel, S.R. (2017). Unexpected high robustness of electrochemical cross-coupling for a broad range of current density. Sci. Adv. 3, eaao3920.

7. Chen, Y., Tian, B., Cheng, Z., Li, X., Huang, M., Sun, Y., Liu, S., Cheng, X., Li, S., and Ding, M. (2021). Electro-Descriptors for the Performance Prediction of ElectroOrganic Synthesis. Angew. Chem. 133, 4245-4253.

8. Navarro, M. (2017). Recent advances in experimental procedures for electroorganic synthesis. Current Opinion in Electrochemistry 2, 43-52.

9. Rauen, A.L., Weinelt, F., and Waldvogel, S.R. (2020). Sustainable electroorganic synthesis of lignin-derived dicarboxylic acids. Green Chem. 22, 5956-5960.

10. Zhang, P., Sheng, X., Chen, X., Fang, Z., Jiang, J., Wang, M., Li, F., Fan, L., Ren, Y., Zhang, B., et al. (2019). Paired Electrocatalytic Oxygenation and Hydrogenation of Organic Substrates with Water as the Oxygen and Hydrogen Source. Angew. Chem. Int. Ed. 58, 9155-9159.

11. Akhade, S.A., Singh, N., Gutiérrez, O.Y., Lopez-Ruiz, J., Wang, H., Holladay, J.D., Liu, Y., Karkamkar, A., Weber, R.S., Padmaperuma, A.B., et al. (2020). Electrocatalytic Hydrogenation of Biomass-Derived Organics: A Review. Chem. Rev. 120, 11370-11419.

12. Zhao, H., Lu, D., Wang, J., Tu, W., Wu, D., Koh, S.W., Gao, P., Xu, Z.J., Deng, S., Zhou, Y., et al. (2021). Raw biomass electroreforming coupled to green hydrogen generation. Nat Commun 12, 2008. 
13. Lucas, F.W.S., Grim, R.G., Tacey, S.A., Downes, C.A., Hasse, J., Roman, A.M., Farberow, C.A., Schaidle, J.A., and Holewinski, A. (2021). Electrochemical Routes for the Valorization of Biomass-Derived Feedstocks: From Chemistry to Application. ACS Energy Letters, 66.

14. Holzhäuser, F.J., Mensah, J.B., and Palkovits, R. (2020). (Non-)Kolbe electrolysis in biomass valorization - a discussion of potential applications. Green Chem. 22, 286301.

15. Leech, M.C., and Lam, K. (2020). Electrosynthesis Using Carboxylic Acid Derivatives: New Tricks for Old Reactions. Acc. Chem. Res. 53, 121-134.

16. Schäfer, H.-J. (1990). Recent contributions of kolbe electrolysis to organic synthesis. In Electrochemistry IV Topics in Current Chemistry., E. Steckhan, ed. (SpringerVerlag), pp. 91-151.

17. Faraday, M. (1834). Siebente Reihe von Experimental-Untersuchungen über Elektricität. Ann. Phys. Chem. 109, 433-451.

18. Zersetzung der Valeriansäure durch den elektrischen Strom (1848). Ann. Chem. Pharm. 64, 339-341.

19. Vijh, A.K., and Conway, B.E. (1967). Electrode Kinetic Aspects of the Kolbe Reaction. Chem. Rev. 67, 623-664.

20. Conway, B.E., and Dzieciuch, M. (1963). NEW APPROACHES TO THE STUDY OF ELECTROCHEMICAL DECARBOXYLATION AND THE KOLBE REACTION: PART I. THE MODEL REACTION WITH FORMATE. Can. J. Chem. 41, 21-37.

21. Conway, B.E., and Vijh, A.K. (1967). Energetics and electrode potentials for steps in the kolbe electrosynthesis: A critique. Electrochimica Acta 12, 102-104.

22. Klocke, E., Matzeit, A., Gockeln, M., and Schäfer, H.J. (1993). Electroorganie Synthesis, 55[1]. Influences on the Selectivity of the Kolbe versus the Non-Kolbe Electrolysis in the Anodic Decarboxylation of Carboxylic Acids. Chem. Ber. 126, 1623-1630.

23. School of Materials Science and Engineering, Harbin University of Science and Technology, Harbin 150040, China, and Yu, Z. (2021). In-Situ and Real-Time Monitoring of Oxygen Evolution during Kolbe Reaction by Scanning Electrochemical Microscopy. Int. J. Electrochem. Sci., 210240.

24. Nilges, P., dos Santos, T.R., Harnisch, F., and Schröder, U. (2012). Electrochemistry for biofuel generation: Electrochemical conversion of levulinic acid to octane. Energy Environ. Sci. 5, 5231-5235. 
25. Qiu, Y., Lopez-Ruiz, J.A., Sanyal, U., Andrews, E., Gutiérrez, O.Y., and Holladay, J.D. (2020). Anodic electrocatalytic conversion of carboxylic acids on thin films of $\mathrm{RuO} 2$, IrO2, and Pt. Applied Catalysis B: Environmental 277, 119277.

26. Yuan, G., Wang, L., Zhang, X., Luque, R., and Wang, Q. (2019). Core-Shell Pt@Ir Nanothorns on Carbon Fiber Paper Electrodes for Carboxylic Acid Valorization via Kolbe Electrolysis. ACS Sustainable Chem. Eng. 7, 18061-18066.

27. Klüh, D., Waldmüller, W., and Gaderer, M. (2021). Kolbe Electrolysis for the Conversion of Carboxylic Acids to Valuable Products-A Process Design Study. Clean Technol. 3, 1-18.

28. Dickinson, T., and Wynne-Jones, W.F.K. (1962). Mechanism of Kolbe's electrosynthesis. Part 1._Anode potential phenomena. Trans. Faraday Soc. 58, 382387.

29. Dickinson, T., and Wynne-Jones, W.F.K. (1962). Mechanism of Kolbe's electrosynthesis. Part 2.-Charging curve phenomena. Trans. Faraday Soc. 58, 388399.

30. Dickinson, T., and Wynne-Jones, W.F.K. (1962). Mechanism of Kolbe's electrosynthesis. Part 3.-Theoretical discussion. Trans. Faraday Soc. 58, 400-404.

31. Gilroy, D., and Conway, B.E. (1965). Kinetic Theory of Inhibition and Passivation in Electrochemical Reactions. J. Phys. Chem. 69, 1259-1267.

32. Bagotzky, V.S., and Vasilyev, Yu.B. (1964). Some characteristics of oxidation reactions of organic compounds on platinum electrodes. Electrochimica Acta 9, 869882.

33. Fioshin, M.Ya., and Vasil'ev, Yu.B. (1963). Kinetics of anodic and chemical reactions in Kolbe's electrosynthesis. Russ Chem Bull 12, 393-400.

34. Brown, A.C., and Walker, J. (1891). Elektrolytische Synthese zweibasischer Säuren. Justus Liebigs Annalen der Chemie 261, 107-128.

35. Shukla, S., and Walker, O. (1931). Formation of methane during the electrolysis of potassium acetate, and the mechanism of Kolbe's electro-synthesis. Transactions of the Faraday Society 27, 35-40.

36. Shukla, S.N., and Walker, O.J. (1932). Anode phenomena in the electrolysis of potassium acetate. Part III. Formation of methane. Transactions of the Faraday Society $28,457-462$.

37. Fleischmann, M., Mansfield, J., and Wynne-Jones, Lord (1965). The anodic oxidation of aqueous solutions of acetate ions at smooth platinum electrodes: part II. The nonsteady state of the kolbe synthesis of ethane. Journal of Electroanalytical Chemistry (1959) 10, 522-537. 
38. Vassiliev, Y.B., and Grinberg, V. (1991). Adsorption kinetics of electrode processes and the mechanism of Kolbe electrosynthesis: Part III. Mechanism of the process. Journal of electroanalytical chemistry and interfacial electrochemistry 308, 1-16.

39. Cerviño, R.M., Triaca, W.E., and Arvía, A.J. (1984). Phenomenology related to the kinetics of Kolbe electrosynthesis. Journal of Electroanalytical Chemistry and Interfacial Electrochemistry 172, 255-264.

40. Vasini, E., and Giordano, M. (1989). Voltammetric study of competitive processes and detection of reaction intermediates in the kolbe reaction at $\mathrm{Pt}$ electrodes. Electrochimica acta 34, 577-585.

41. Vijh, A., and Conway, B. (1967). Potentiostatic and potentiodynamic studies on the kolbe electro-synthesis. Fresenius' Zeitschrift für analytische Chemie 230, 81-95.

42. Conway, B., and Dzieciuch, M. (1963). New Approaches to the Study of Electrochemical Decarboxylation and the Kolbe Reaction: Part II. The Model Reaction with Trifluoroacetate and Comparisons with Aqueous Solution Behavior. Canadian Journal of Chemistry $41,38-54$.

43. Conway, B., and Dzieciuch, M. (1963). NEW APPROACHES TO THE STUDY OF ELECTROCHEMICAL DECARBOXYLATION AND THE KOLBE REACTION: PART III. QUANTITATIVE ANALYSIS OF DECAY AND DISCHARGE TRANSIENTS AND THE ROLE OF ADSORBED INTERMEDIATES. Canadian Journal of Chemistry 41, 55-67.

44. Bolzán, A.E., and Arvia, A.J. (1994). Changes in the kinetics of the oxygen evolution reaction induced by oxide films at platinum electrodes. Journal of Electroanalytical Chemistry $375,157-162$.

45. Rand, D., and Woods, R. (1972). A study of the dissolution of platinum, palladium, rhodium and gold electrodes in $1 \mathrm{M}$ sulphuric acid by cyclic voltammetry. Journal of Electroanalytical Chemistry and Interfacial Electrochemistry 35, 209-218.

46. T.C.Liu, B.E.C. (1988). Potential relaxation and interfacial capacitance behaviour of the kolbe coupling reaction at Pt. Journal of Electroanalytical Chemistry and Interfacial Electrochemistry.

47. Huang, Y.-F., Kooyman, P.J., and Koper, M.T.M. (2016). Intermediate stages of electrochemical oxidation of single-crystalline platinum revealed by in situ Raman spectroscopy. Nat Commun 7, 12440.

48. Liu, S., Zong, J., Zhao, Z.-J., and Gong, J. (2020). Exploring the initial oxidation of Pt, Pt3Ni, Pt3Au (111) surfaces: a genetic algorithm based global optimization with density functional theory. Green Chemical Engineering 1, 56-62.

49. Jain, A., Ong, S.P., Hautier, G., Chen, W., Richards, W.D., Dacek, S., Cholia, S., Gunter, D., Skinner, D., Ceder, G., et al. (2013). Commentary: The Materials Project: 
A materials genome approach to accelerating materials innovation. APL Materials 1 , 011002.

50. Nong, H.N., Falling, L.J., Bergmann, A., Klingenhof, M., Tran, H.P., Spöri, C., Mom, R., Timoshenko, J., Zichittella, G., Knop-Gericke, A., et al. (2020). Key role of chemistry versus bias in electrocatalytic oxygen evolution. Nature 587, 408-413.

51. Dickens, C.F., Kirk, C., and Nørskov, J.K. (2019). Insights into the Electrochemical Oxygen Evolution Reaction with ab Initio Calculations and Microkinetic Modeling: Beyond the Limiting Potential Volcano. J. Phys. Chem. C 123, 18960-18977.

52. Kelly, S.R., Kirk, C., Chan, K., and Nørskov, J.K. (2020). Electric Field Effects in Oxygen Reduction Kinetics: Rationalizing pH Dependence at the Pt(111), $\mathrm{Au}(111)$, and $\mathrm{Au}(100)$ Electrodes. J. Phys. Chem. C 124, 14581-14591.

53. Chen, L.D., Urushihara, M., Chan, K., and Nørskov, J.K. (2016). Electric Field Effects in Electrochemical $\mathrm{CO}_{2}$ Reduction. ACS Catal. 6, 7133-7139.

54. Vijay, S., Gauthier, J.A., Heenen, H.H., Bukas, V.J., Kristoffersen, H.H., and Chan, K. (2020). Dipole-Field Interactions Determine the $\mathrm{CO}_{2}$ Reduction Activity of $2 \mathrm{D} \mathrm{Fe}-\mathrm{N}-$ C Single-Atom Catalysts. ACS Catal. 10, 7826-7835.

55. Ringe, S., Morales-Guio, C.G., Chen, L.D., Fields, M., Jaramillo, T.F., Hahn, C., and Chan, K. (2020). Double layer charging driven carbon dioxide adsorption limits the rate of electrochemical carbon dioxide reduction on Gold. Nat Commun 11, 33.

56. Vijay, S., Ju, W., Brückner, S., Strasser, P., and Chan, K. Unified Mechanistic Understanding of $\mathrm{CO} 2$ Reduction to $\mathrm{CO}$ on Transition Metal and Single Atom Catalysts. chemrxiv.org. 2021.

57. Weaver, M.J. (1998). Potentials of Zero Charge for Platinum(111)-Aqueous Interfaces: A Combined Assessment from In-Situ and Ultrahigh-Vacuum Measurements. Langmuir 14, 3932-3936.

58. Heinen, M., Jusys, Z., and Behm, R.J. (2010). Ethanol, Acetaldehyde and Acetic Acid Adsorption/Electrooxidation on a Pt Thin Film Electrode under Continuous Electrolyte Flow: An in Situ ATR-FTIRS Flow Cell Study. J. Phys. Chem. C 114, 9850-9864.

59. Fioshin, M.Y., and Vasil'ev, Y.B. (1960). Anode processes in the electrolysis of carboxylic acid salts. In Doklady Akademii Nauk (Russian Academy of Sciences), pp. 879-882.

60. Grabow, L.C., Hvolbæk, B., and Nørskov, J.K. (2010). Understanding Trends in Catalytic Activity: The Effect of Adsorbate-Adsorbate Interactions for CO Oxidation Over Transition Metals. Top Catal 53, 298-310.

61. Lausche, A.C., Medford, A.J., Khan, T.S., Xu, Y., Bligaard, T., Abild-Pedersen, F., Nørskov, J.K., and Studt, F. (2013). On the effect of coverage-dependent adsorbate- 
adsorbate interactions for $\mathrm{CO}$ methanation on transition metal surfaces. Journal of Catalysis 307, 275-282.

62. Conway, B.E., and Vijh, A.K. (1967). Controlled potential studies on the Kolbe reaction and the role of coadsorbed surface oxides. I. Platinum in trifluoroacetate solutions. J. Phys. Chem. 71, 3637-3654.

63. Eberson, L., and NILSSON, S. (1968). Studies on the Kolbe Electrolytic Synthesis. Acta Chem, Scand 22.

64. Sato, N., Sekine, T., and Sugino, K. (1968). Anodic Processes of Acetate Ion in Methanol and in Glacial Acetic Acid at Various Anode Materials. Journal of the Electrochemical Society 115, 242.

65. Damjanovic, A., and Jovanovic, B. (1976). Anodic Oxide Films as Barriers to Charge Transfer in O 2 Evolution at Pt in Acid Solutions. J. Electrochem. Soc. 123, 374-381.

66. Damjanovic, A., Birss, V.I., and Boudreaux, D.S. (1991). Electron Transfer Through Thin Anodic Oxide Films during the Oxygen Evolution Reactions at Pt Electrodes: I . Acid Solutions. J. Electrochem. Soc. 138, 2549-2555.

67. Birss, V.I., and Damjanovic, A. (1987). Oxygen Evolution at Platinum Electrodes in Alkaline Solutions: I. Dependence on Solution pH and Oxide Film Thickness. J. Electrochem. Soc. 134, 113-117.

68. Suen, N.-T., Hung, S.-F., Quan, Q., Zhang, N., Xu, Y.-J., and Chen, H.M. (2017). Electrocatalysis for the oxygen evolution reaction: recent development and future perspectives. Chem. Soc. Rev. 46, 337-365.

69. Patel, A.M., Vijay, S., Kastlunger, G., Nørskov, J.K., and Chan, K. (2021). Generalizable Trends in Electrochemical Protonation Barriers. J. Phys. Chem. Lett. 12, 5193-5200.

70. Pell, W.G., Zolfaghari, A., and Conway, B.E. (2002). Capacitance of the double-layer at polycrystalline $\mathrm{Pt}$ electrodes bearing a surface-oxide film. Journal of Electroanalytical Chemistry 532, 13-23.

71. Glasstone, S., and Hickling, A. (1939). The Hydrogen Peroxide Theory of Electrolytic Oxidation. Chemical Reviews 25, 407-441. 